\title{
Relationship between Antenatal Inflammation and Antenatal Infection Identified by Detection of Microbial Genes by Polymerase Chain Reaction
}

\author{
ROBIN MIRALLES, RACHEL HODGE, PENNY C. MCPARLAND, DAVID J. FIELD, \\ STEPHEN C. BELL, DAVID J. TAYLOR, WILLIAM D. GRANT, AND SAILESH KOTECHA \\ Reproductive Sciences Section [R.M., R.H., P.C.M., S.C.B., D.J.T., S.K.], Department of Cancer Studies \\ and Molecular Medicine, Leicester LE2 7LX, UK, Department of Epidemiology and Public Health \\ [D.J.F.], Division of Microbiology and Immunology [W.D.G.], Department of Infection, Immunity and \\ Inflammation, University of Leicester, Leicester LE1 9HN, UK
}

\begin{abstract}
ABST
Although antenatal infection is thought to play an important
role in the pathogenesis of preterm labor and neonatal diseases,
the exact mechanisms are largely unknown. We sought to clarify
the relationship between antenatal infection and intrauterine and
neonatal inflammation. Samples were obtained from 41 preterm
infants of <33 wk gestation delivered to 36 mothers and ana-
lyzed for the presence of 16 s ribosomal RNA (16s rRNA) genes
using PCR and for the proinflammatory cytokines IL-6 and IL-8.
In 16 (44\%) mother-baby pairings, at least one sample was found
to be positive for the presence of 16 sRNA genes. All but one of
the positive samples were from mothers presenting with preterm
prelabor rupture of membranes (pPROM) or in spontaneous
idiopathic preterm labor. A strong association was found be-
tween the presence of 16 sRNA genes and chorioamnionitis and
with funisitis. A marked increase in IL-6 and IL-8 was noted in
all tissues positive for 16s rRNA genes, including placenta, fetal
\end{abstract}
Preterm birth is the most common cause of neonatal death (1) and is associated with increased neonatal morbidity and childhood disability $(2,3)$. Evidence from studies over the past two decades suggests that subclinical infection and inflammation of the amnion/chorion/decidua is implicated in the pathogenesis of pPROM and "spontaneous" preterm labor $(4,5)$. More recently, intrauterine infection/inflammation has been associated with neonatal morbidity, including white matter cerebral lesions (6-8) and CLD (9-11). It has been estimated that as many as $40 \%$ of spontaneous preterm births may be attributed to antenatal infection (12). Furthermore, because many infections are subclinical and the women have often been treated with antibiotics, culture results may underestimate the "true" infection rates.

Received January 27, 2004; accepted August 10, 2004.

Correspondence: Sailesh Kotecha, FRCPCH Ph.D., Department of Child Health, Cardiff University, Cardiff, CF14 4XN, UK; e-mail: sk43@le.ac.uk

DOI: 10.1203/01.PDR.0000155944.48195.97 membranes, cord blood serum, and, where samples were available, in bronchoalveolar lavage fluid (BAL) and in amniotic fluid. Interestingly, gastric fluid was always positive for $16 \mathrm{~s}$ rRNA genes if any other intrauterine or BAL sample was positive, suggesting that this sample may provide an alternative to amniotic fluid to identify antenatal infection. In conclusion, we have found that microbial genes are particularly prevalent in pPROM and spontaneous preterm labor groups and that their presence is strongly associated with a marked intrauterine inflammatory response. (Pediatr Res 57: 570-577, 2005)
Abbreviations
BAL, bronchoalveolar lavage
CLD, chronic lung disease
pPROM, preterm prelabor rupture of membranes
rRNA, ribosomal RNA

Many studies have used amniotic fluid to identify antenatal intrauterine infection. The organisms commonly identified are vaginal commensals, suggesting ascending infection as a route of entry to the uterine cavity (13). Few studies have investigated other components of the uterine cavity to accurately identify the presence of infection and the nature of the relationship between such infection and inflammation. A clear association has been demonstrated between chorioamnionitis and intrauterine infection (14-16). Often, intrauterine inflammation, including chorioamnionitis, is considered synonymous with intrauterine infection $(4,17)$. However, in many cases of chorioamnionitis it has not been possible to culture bacteria from a significant proportion of placentas, fetal membranes, and amniotic fluid samples (14-16).

The identification of conserved microbial genes (e.g. ribosomal genes) to detect bacteria is a technique that has been applied to amniotic fluid successfully to improve this yield (18-21). We have applied such technology to lung lavage fluid from preterm infants. By detecting microbial 16s ribosomal 
RNA genes using PCR with subsequent cloning and sequencing, we have identified a variety of organisms in infants who are chronically ventilated (22). In addition, we used specific PCR primers to demonstrate the relationship between Ureaplasma urealyticum (U. urealyticum) and pulmonary inflammation (22).

To clarify the relationship between antenatal infection, inflammation, and the pathogenesis of preterm labor, we had three aims: a) to detect microbes by identifying the presence of 16s rRNA genes by applying PCR to placenta, fetal membranes, and, wherever possible, amniotic fluid, cord blood serum, gastric fluid, and BAL fluid obtained from preterm deliveries of $<33$ wk gestation; b) to relate the presence of microbes with the proinflammatory cytokine IL- 6 and potent neutrophil chemotactic factor IL-8, which have both previously been shown to be increased in preterm labor (23-25); and c) to compare the prevalence of infection in the subgroups of preterm delivery-i.e. i) $\mathrm{pPROM}$, ii) spontaneous preterm labor, iii) preterm deliveries due to maternal or fetal reasons, and iv) preterm twin deliveries.

\section{METHODS}

Patient population. All mothers likely to deliver at $<33$ wk gestation were invited to join the study over a 15 -mo period from January 2001. Only one mother refused consent and samples were obtained whenever the research fellow was informed of imminent preterm delivery. The study was approved by the Leicestershire Research Ethics Committee and written informed consent was obtained from all mothers. A placental and fetal membrane sample was obtained from almost all deliveries and, wherever possible, serum from cord blood and a sample of cord, amniotic fluid (mainly at cesarean section), gastric fluid, and BAL fluid from infants requiring mechanical ventilation were obtained. Three fetal membrane rolls from placental edge to rupture line (each approximately $2 \mathrm{~cm} \times 10 \mathrm{~cm}$ ) with the edge of the chorionic plate innermost, three sections of placenta (inner, mid-section, and outer chorionic plate), and three sections through the umbilical cord were collected. Both formalin-fixed, wax-embedded and snap liquid nitrogen frozen tissues samples were obtained. BAL fluid was obtained immediately after birth, wherever possible, from infants requiring mechanical ventilation, as previously described (26-28). Gastric fluid was obtained after routine passage of FG 6-8 nasogastric tube as soon after delivery as possible. All gastric fluid samples were obtained within $1 \mathrm{~h}$ of delivery and before any milk feeds. All fluid samples were centrifuged and separated and the cell pellet and supernatant were stored at $-70^{\circ} \mathrm{C}$ for later analysis.

Placental and umbilical cord histology. It is our routine practice for all placentas and membranes to be examined by our pediatric pathologist, who was blinded as to the sample origins. Chorioamnionitis was diagnosed in the presence of an acute inflammatory infiltrate in the fetal membrane roll or chorionic plate (29). Funisitis was defined as presence of neutrophil infiltration into the umbilical walls or Wharton's jelly and graded as one-, two-, or three-vessel funisitis (30).

Detection of presence of microbial 16s RNA genes by PCR. DNA was extracted from all tissues, including placenta, fetal membranes, and cell pellets from fluid samples using a commercially available RNA/DNA extraction kit (QIAGEN, Dorking, Surrey, UK). The integrity of each DNA sample was confirmed by identifying the presence of $\beta$-actin, as previously described $(22,27)$. Sequences for 16 s rRNA genes were amplified by PCR using the primers FD1 (AGA GTT TGA TCC TGG CTC AG) and rP1 (ACG G(T/A/ C)T ACC TTG TTA CGA CTT) at concentrations of $0.2 \mu \mathrm{M}$ in the presence of TaqDNA Polymerase (Abgene, Epsom, Surrey, UK), as previously described (22). The DNA template was then added to the PCR mixes including the primers described above and subjected to $95^{\circ} \mathrm{C}$ for $2 \mathrm{~min}$ followed by 30 cycles at $95^{\circ} \mathrm{C}$ for $30 \mathrm{~s}, 55^{\circ} \mathrm{C}$ for $40 \mathrm{~s}$, and $72^{\circ} \mathrm{C}$ for 2 min followed by a 10 -min extension cycle at $72^{\circ} \mathrm{C}$. The reaction products were separated by electrophoresis on $1.2 \%$ agarose gels stained with ethidium bromide and visualized using UV illumination. The PCR DNA products were cut from the gel, purified using the QIAquick gel extraction system (QIAGEN), and sequenced. In most cases, single organisms were identified by identifying 400-500 base pairs (using Chromas software, version 1.45, Griffith University, Queensland, Australia) and the closest relatives for the sequence by BLAST searches of databases posted at http://www.ncbi.nlm.nih.gov/ to ensure the same results were obtained on each occasion. The repeatability of the technique was assessed by reanalyzing all positive and a selection of negative samples. Repeatability of the results was also ensured in the development phase and in a previous study (22).

Detection of U. urealyticum by using specific primers. PCR was applied to all samples to detect presence of $U$. urealyticum by using specific primers to the urease gene (U5-CAA TCT GCT CGT GAA GTA TTA C and U4-ACG ACG TCC ATA AGC AAC T) as previously described $(22,31)$. Amplification by PCR with these primers resulted in a 428 bp product fragment of the components UreA and UreB of the U. urealyticum urease complex. Amplification was carried out using TaqDNA Polymerase (Abgene) at $95^{\circ} \mathrm{C}$ for $2 \mathrm{~min}$ followed by 30 cycles of $95^{\circ} \mathrm{C}$ for $30 \mathrm{~s}, 55^{\circ} \mathrm{C}$ for $40 \mathrm{~s}$, and $72^{\circ} \mathrm{C}$ for $1 \mathrm{~min}$ followed by a $10-\mathrm{min}$ extension cycle at $72^{\circ} \mathrm{C}$. The reaction products were separated by agarose gel electrophoresis and the presence or absence of bands was identified by examination of the gels under UV illumination.

Measurement of IL-6 and IL-8 in tissues and fluid samples. IL-6 and IL-8 were estimated in supernatants using commercially available kits as per manufacturer's instructions (R \& D Systems Europe, Oxford, UK). The lowest detection limit for undiluted samples was $0.7 \mathrm{pg} / \mathrm{mL}$ for IL- 6 and $10 \mathrm{pg} / \mathrm{mL}$ for IL-8. Total protein was extracted from placenta and from fetal membranes after homogenizing in HEPES buffer and sonication as previously described (32). IL- 6 and IL- 8 were measured by ELISA as above and the results expressed as picograms per milligram of protein.

Statistical analysis. The number of mother-baby dyads that needed to be studied was estimated by assuming that there would be a $70 \%$ concordance between the presence of antenatal infection (defined as presence of 16s rRNA genes in intrauterine samples) and the presence of inflammation (defined as IL-8 $>20 \mathrm{pg} / \mathrm{mL}$ ) and a $70 \%$ concordance between lack of 16s rRNA genes and inflammation. To achieve a power of $80 \%$ at $p<0.05$ level, it was estimated that 36 mother-baby pairings would need to be studied. Data are expressed as medians \pm interquartile ranges (IQR). The data for IL-6 and IL-8 are given as picograms per milliliter of fluid and for solid tissues as picograms per milligram of protein. The nonparametric tests Kruskal-Wallis test was used to compare multiple groups and the Mann-Whitney $U$ test to compare two unrelated groups. Fisher's exact test was used to compare associations between the presence of microbial material and the presence of funisitis or chorioamnionitis or the development of CLD of prematurity, defined as oxygen dependency at $28 \mathrm{~d}$ of age using a two-by-two or four-by-two table as appropriate.

\section{RESULTS}

Patient characteristics and samples collected. Forty-one preterm infants of $<33$ wk gestation born to 36 mothers were recruited. Of these, 10 infants were delivered to mothers with pPROM with membrane rupture occurring at least $1 \mathrm{~h}$ before onset of labor; 10 to mothers with spontaneous onset of preterm labor with intact membranes at onset of labor; 11 infants were delivered by cesarean section before the onset of labor for maternal (severe preeclampsia) or fetal reasons (compromised fetal growth or umbilical doppler flow abnormalities); and 5 mothers delivered preterm twins. The membranes were intact or had ruptured for $<12 \mathrm{~h}$ before onset of labor in the twin pregnancies. Thirteen mothers had received antenatal treatment with antibiotics, including 8 presenting with pPROM, 2 with spontaneous preterm labor, and 1 with preterm twins.

Amniotic fluid was available from 14 deliveries. Gastric fluid was obtained soon after delivery from 29 infants. BAL fluid was obtained on the first day of life in 21 infants who required mechanical ventilation for respiratory disease. It was expected that the microbiology of gastric fluid and BAL fluid would reflect amniotic fluid microbiology as fetal lung fluid, gastric fluid, and amniotic fluid may be in continuity in utero. In this way, a fluid sample representative of the amniotic cavity was obtained in all but one delivery. Samples of chorionic plate and fetal membrane tissue were also obtained from most deliveries. 
Detection of 16s rRNA genes. From all deliveries, 16 had at least one sample positive for the presence of 16s rRNA (Table 1). It will be noted that, except for one sample showing a mixture of microbes in the placenta from the nonlaboring group delivered due to maternal or fetal reasons, all the remaining positive samples were either in the pPROM or spontaneous preterm labor groups (Table 1). There were a variety of organisms identified from DNA sequencing of the positive samples. U. urealyticum was the most common organism identified and often was identified in multiple samples from the same mother-baby pairings. The other organisms identified are shown in Table 1. Some of these have been previously shown to be common vaginal organisms (e.g. Gardnerella vaginalis). Organisms, such as Fusobacterium nucleatum, have previously been implicated in the pathogenesis of preterm labor (33). In some instances, we were only able to state that a variety of organisms were present. Microbial 16s rRNA genes were most frequently identified in fetal membranes $(n=9)$ and in gastric fluid $(n=8)$, but as there were missing samples, especially for amniotic fluid and BAL fluid (which was only obtained if the infants was ventilated), only a few samples were positive (Table 1).

Evidence of infection was detected in all cases where there was evidence of chorioamnionitis or funisitis. There were four cases in which infection was detected but there was no evidence of chorioamnionitis or funisitis. Interestingly, all of these were from the spontaneous preterm labor groups (Table 1). In two of these, significant deciduitis was noted, whereas in the other two there was no histologic evidence of inflammation.

Identification of 16s rRNA genes in gastric fluid. Adequate samples of gastric fluid were obtained from 29 infants. In this subset, the delivery of eight infants was associated with cho-

Table 1. Presence of 16s RNA genes shown by applying PCR to samples obtained from women with preterm deliveries

\begin{tabular}{|c|c|c|c|c|c|}
\hline Delivery & $\begin{array}{l}\text { 16S rRNA } \\
\text { positive }\end{array}$ & Positive samples & Microbe identified & Chorionoamnionitis & Funisitis \\
\hline PPROM & Yes & $\mathrm{GF}, \mathrm{FM}$ & $\mathrm{Uu}, \mathrm{Uu}$ & Yes & $3 \mathrm{bv}$ \\
\hline PPROM & Yes & FM & Mix & Yes & $3 \mathrm{bv}$ \\
\hline PPROM & Yes & BAL & Sau & Yes & $2 \mathrm{bv}$ \\
\hline pPROM & Yes & PL, GF & Mix, Sp & Yes & $3 \mathrm{bv}$ \\
\hline pPROM & Yes & BAL, GF, FM & $\mathrm{Uu}, \mathrm{Uu}, \mathrm{Uu}$ & Yes & $3 \mathrm{bv}$ \\
\hline pPROM & No & & & No & No \\
\hline pPROM & No & & & No & No \\
\hline Spontaneous preterm labor & Yes & PL & Mix & No & No \\
\hline Spontaneous preterm labor & Yes & PL, BAL, GF, FM & Fn, Fn, Fn, Fn & Yes & $3 \mathrm{bv}$ \\
\hline Spontaneous preterm labor & Yes & FM & $\mathrm{Uu}$ & No & No \\
\hline Spontaneous preterm labor & Yes & BAL & Mix & No & No \\
\hline Spontaneous preterm labor & No & & & No & No \\
\hline Spontaneous preterm labor & No & & & No & No \\
\hline Nonlaboring delivery & Yes & PL & Mix & No & No \\
\hline Nonlaboring delivery & No & & & No & No \\
\hline Nonlaboring delivery & No & & & No & No \\
\hline Nonlaboring delivery & No & & & No & No \\
\hline Nonlaboring delivery & No & & & No & No \\
\hline Nonlaboring delivery & No & & & No & No \\
\hline Nonlaboring delivery & No & & & No & No \\
\hline Nonlaboring delivery & No & & & No & No \\
\hline Nonlaboring delivery & No & & & No & No \\
\hline Nonlaboring delivery & No & & & No & No \\
\hline Nonlaboring delivery & No & & & No & No \\
\hline Preterm twin delivery & No & & & No & No \\
\hline Preterm twin delivery & No & & & No & No \\
\hline
\end{tabular}

Asp, Acinetobacter sp.; AF, amniotic fluid; bv, number of blood vessels involved; BAL, bronchoalveolar lavage fluid; Fn, Fusobacterium nucleatum; FM, fetal membrane; Gv, Gardnerella vaginalis; GF, gastric fluid; La, Leptotrichia amnionii; Ph, Peptostreptococcus hareii; PL, placenta; Sag, Streptococcus agalactiae; Sp, Streptococcus pneumoniae/milleri; Sau, Staphylococcus aureus; Uu, Ureaplasma urealyticum. 
rioamnionitis or funisitis. There was no histologic evidence of inflammation in the remaining 21. By applying PCR to gastric fluid samples to detect 16s rRNA genes, microbes were detected in all cases of chorioamnionitis. No organisms were detected in the remaining cases without chorioamnionitis. Interestingly, the gastric fluid samples were always positive if any other intrauterine sample was also noted to be positive.

Culture results. Only four women were positive on routine bacterial cultures, with two each in the pPROM and spontaneous preterm labor groups. Two placental swabs grew Streptococcus pneumoniae and Enterococcus spp. and two amniotic fluid samples grew Streptococcus milleri and G. vaginalis. The corresponding results by using $16 \mathrm{~s}$ rRNA were $S$. pneumoniae in gastric fluid but mixed species from placenta; $F$. nucleatum (an Enterococcus spp.) 16s rRNA genes isolated from placenta, fetal membranes, BAL fluid, and gastric fluid; mixed species from fetal membranes; and G. vaginalis in amniotic fluid. Thus, the detection of 16s rRNA genes identified those organisms cultured and also identified the presence of other microbial genes in several samples (Table 1).

Relationship of clinical characteristics and inflammation to detection of 16s rRNA genes. When we compared the clinical characteristics of the women-baby pairings who had at least one positive sample for 16s rRNA genes, we were unable to find any differences in the use of antenatal dexamethasone, mode of delivery, need for mechanical ventilation, use of surfactant, or development of respiratory distress syndrome or CLD of prematurity (Table 2). Although there appears to be lower incidence of CLD in the 16s RNA genes-positive group, this difference is not significant and is likely to be due to the small numbers studied. One infant died from respiratory failure at $24 \mathrm{~h}$ (gestation $25 \mathrm{wk}$, birth weight $730 \mathrm{~g}$ ) and $U$. urealyticum and Peptostreptococcus were identified in gastric fluid and Acinetobacter in fetal membrane. There were marked differences in inflammatory responses between the 16S rRNA group positive and negative groups. Marked differences in inflammatory responses between the two groups with highly significant differences were noted for IL-6 in placenta $(p<0.0001)$, fetal membranes $(p<0.0001)$, cord blood serum $(p<0.0001)$, amniotic fluid $(p<0.01)$, and d-1 BAL fluid $(p<0.05)$ (Figs.

Table 2. Patient characteristics of preterm deliveries with at least one sample positive for 16s rRNA genes

\begin{tabular}{lcc}
\hline & $\begin{array}{c}\text { Positive for 16s } \\
\text { rRNA genes }\end{array}$ & $\begin{array}{c}\text { Negative for 16s } \\
\text { rRNA genes }\end{array}$ \\
\hline Number & 16 & 25 \\
Gestation (wk) & $29(24-32)$ & $30(26-32)$ \\
Birth weight (g) & $1220(610-2070)$ & $1150(780-2050)$ \\
Antenatal dexamethasone & $15 / 16(94 \%)$ & $24 / 25(96 \%)$ \\
Surfactant & $10 / 16(63 \%)$ & $16 / 25(64 \%)$ \\
Cesarean section & $7 / 16(44 \%)$ & $17 / 25(68 \%)$ \\
Infant respiratory support & $11 / 16(69 \%)$ & $18 / 25(72 \%)$ \\
RDS & $10 / 16(63 \%)$ & $16 / 25(64 \%)$ \\
CLD at 28 d & $5 / 15 * *(33 \%)$ & $11 / 25(44 \%)$ \\
CLD at 36 wk & $2 / 15 * *(13 \%)$ & $9 / 25(36 \%)$ \\
Chorioamnionitis* & $11 / 16(69 \%)$ & $0 / 25(0 \%)$ \\
Funisitis* & $10 / 16(63 \%)$ & $0 / 25(0 \%)$ \\
\hline
\end{tabular}

RDS, respiratory distress syndrome.

$* p$ Value $<0.0001$

** One infant death at $24 \mathrm{~h}$.

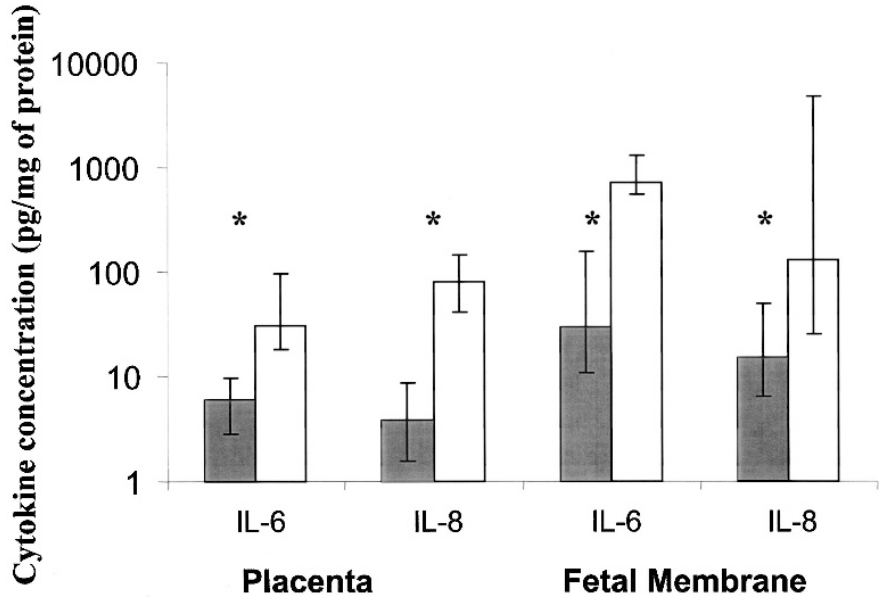

Figure 1. Concentration of IL-6 and IL-8 in placenta and fetal membrane in the group negative (shaded bars) and positive (open bars) for 16s rRNA genes. Concentration of cytokine is given per milligram of protein. $* p<0.0001$.

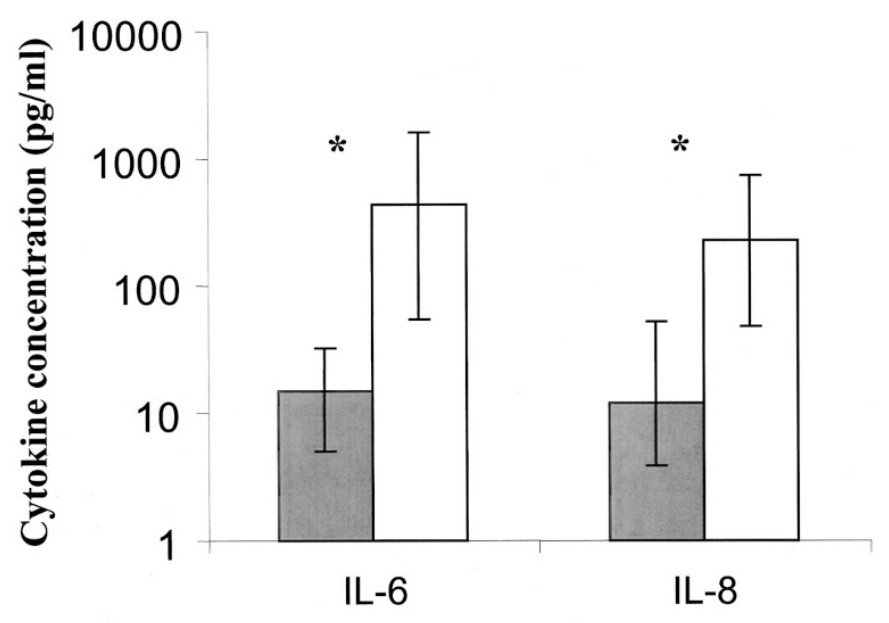

\section{Cord Blood}

Figure 2. Concentration of IL-6 and IL-8 in cord blood in the group negative (shaded bars) and positive (open bars) for 16s rRNA genes. ${ }^{*} p<0.0001$.

1-3). The results were very similar for IL-8 in the same samples in that marked statistical differences were noted between the two groups in placenta $(p<0.0001)$, fetal membranes $(p<0.0001)$, cord blood serum $(p<0.0001)$, amniotic fluid $(p<0.01)$, and d-1 BAL fluid $(p<0.05)$ (Figs. 1-3). Because twin pregnancies may have a different mechanism for initiating labor, we reanalyzed the data excluding these infants and found that significant differences remained for all samples for both IL-6 and IL-8.

Preterm labor groups. We divided the mother-baby pairings into four delivery groups, namely i) pPROM, ii) spontaneous preterm labor group, iii) preterm delivery by cesarean section for maternal or fetal reasons, and iv) preterm twin deliveries. The patient characteristics are shown in Table 3 . There were no significant differences between the groups for gestational age, birth weight, antenatal dexamethasone use, ventilation, neonatal respiratory distress syndrome, need for mechanical ventilation, or CLD of prematurity defined as oxygen dependency at either $28 \mathrm{~d}$ or $36 \mathrm{wk}$ postconceptual age. However, when we 


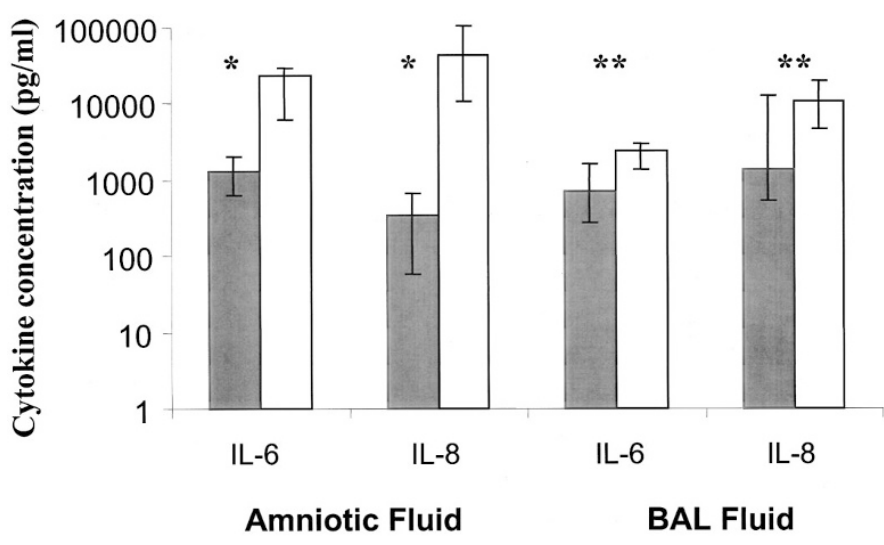

Figure 3. Concentration of IL- 6 and IL- 8 in amniotic fluid and BAL fluid in the group negative (shaded bars) and positive (open bars) for 16s rRNA genes. $* p<0.01, * * p<0.05$.

searched for antenatal infection by identifying the presence of 16s rRNA genes, the positive samples were found in the pPROM (7/10) and spontaneous preterm labors groups (8/10), with only one positive sample found in the nonlaboring group (which identified mixed growth in placenta). Furthermore, the cytokines IL-6 and IL- 8 were markedly increased in placental tissue, fetal membranes, and cord blood serum from the pPROM and spontaneous preterm labor groups when compared with the twin deliveries and nonlaboring groups (all $p<$ 0.05) (Figs. 4-6). Few samples were available for amniotic fluid and BAL fluid from each group but there was a trend toward differences, with the highest concentrations of IL- 6 and IL-8 seen in the pPROM and spontaneous labor groups.

\section{DISCUSSION}

This study examined the detection of microbes associated with preterm delivery using PCR detection of genes for $16 \mathrm{~S}$ rRNA. It compared the results with the histologic presence of chorioamnionitis, and the levels of IL-6 and IL-8 in placental tissue, fetal membranes, and cord blood serum in deliveries at $<33$ wk gestation classified according to type of labor (pPROM, preterm labor, or elective delivery). By confining the work to deliveries at earlier gestation, we increased the likelihood of including infection-related deliveries (34-35). Although numerous studies have compared standard microbial culture techniques with histologic chorioamnionitis (14$16,36)$, cytokines with culture techniques (37-41), and cytokines with histologic chorioamnionitis (42-46), none has compared all parameters and included both fetal and maternal tissues from all subclassifications of preterm delivery.

By using PCR to examine for evidence of microbes, we have confirmed a higher rate of detection of infection associated with spontaneous preterm delivery than detected by standard culture techniques. Seventy percent of deliveries following pPROM and $80 \%$ of deliveries following preterm labor were associated with the presence of microbial rRNA in at least one tissue/fluid sample. Microbes were identified in samples from all deliveries with histologic chorioamnionitis, and in samples from four deliveries with no evidence of chorioamnionitis. However, two of these cases were associated with deciduitis, therefore, the presence of bacteria within the decidual component of the fetal membrane homogenate may have been detected by PCR. Where multiple samples from the same motherbaby pair were present, good correspondence between microbes identified was observed. Correspondence was also observed between microbes identified by standard culture techniques and those identified by PCR, suggesting that the technique is robust. Chorioamnionitis was present in $60 \%$ of deliveries arising from pPROM and $40 \%$ of deliveries following preterm labor. Chorioamnionitis has previously been associated with $36-60 \%$ of placentas resulting from preterm labor with intact membranes $(14,16,47)$ compared with $42-80 \%$ of placentas after pPROM $(15,45,48)$. Only a proportion of cases of chorioamnionitis have been associated with microbes isolated from either placenta (14) or amniotic fluid (16). It has therefore been suggested that an inflammatory response and chorioamnionitis may occur in the absence of infection (16). However, the outcomes of pregnancies in women with an intrauterine inflammatory response but negative amniotic fluid culture did not differ from those with a positive amniotic fluid culture (29). The increased detection of microbes by PCR in this study would suggest that this former group is also likely to represent amniotic fluid infection. The increased detection rate of infection by PCR would suggest that almost all cases of chorioamnionitis following early preterm delivery are infection related. It is possible that differences between standard culture techniques and PCR may be due to variation in bacterial load, due to surface swabs being taken for culture as opposed to whole extracts used for detecting microbial 16s rRNA genes or difficulty in culturing many fastidious organisms that need specific culture media and conditions. Additionally, in this study, unlike in many others, we have selected only preterm deliveries of $<33 \mathrm{wk}$.

Several studies have applied universal bacterial PCR to amniotic fluid obtained by amniocentesis from women in preterm labor $(19,20)$ or following premature rupture of membranes (18). In one study, the sensitivity for the detection of infection by PCR was $95 \%$ compared with $76 \%$ by bacterial culture (19) and in another PCR detected infection in 55.5\% and culture in $9.2 \%$ (20). These studies are not directly comparable to ours as they applied PCR techniques to amniotic fluid to detect infection, whereas ours relied on both fluid samples and solid tissues, including those where a histologic inflammatory response, namely chorioamnionitis and funisitis, was observed.

This work suggests similar infection rates in preterm labor and pPROM, although the group sizes are very small. Previous work has suggested a higher rate of both chorioamnionitis and intrauterine infection associated with pPROM than with spontaneous preterm labor. However, some of the work on pPROM involves examination of tissues obtained after labor and delivery, and following a latency period after membrane rupture, and thus may by considered to reflect infection acquired after membrane rupture. Ghidini et al. (49), however, found that the duration of the latency period in pPROM did not increase the rate of inflammation in placenta, fetal membranes, or cord examined after delivery. Our work, although having very small numbers, also supports previous work suggesting infection is 
Table 3. Patient characteristics classified according to type of preterm delivery

\begin{tabular}{|c|c|c|c|c|}
\hline & pPROM & $\begin{array}{l}\text { Spontaneous } \\
\text { preterm labor }\end{array}$ & $\begin{array}{c}\text { Nonlaboring } \\
\text { delivery }\end{array}$ & $\begin{array}{c}\text { Preterm twin } \\
\text { delivery }\end{array}$ \\
\hline Number & 10 & 10 & 11 & 10 \\
\hline No. 16s rRNA positive & $7(70 \%)$ & $8(80 \%)$ & $1(9 \%)$ & $0(0 \%)$ \\
\hline Birth weight (g) & $1470(610-2050)$ & $1220(670-2070)$ & $1090(780-1942)$ & $1175(900-1560)$ \\
\hline Antenatal dexamethasone & $9 / 10(90 \%)$ & $9 / 10(90 \%)$ & $11 / 11(100 \%)$ & $10 / 10(100 \%)$ \\
\hline Surfactant & $5 / 10(50 \%)$ & $8 / 10(80 \%)$ & $7 / 11(64 \%)$ & $6 / 10(60 \%)$ \\
\hline RDS & $5 / 10(50 \%)$ & $8 / 10(80 \%)$ & $7 / 11(64 \%)$ & $6 / 10(60 \%)$ \\
\hline CLD at $28 \mathrm{~d}$ & $2 / 9 * *(22 \%)$ & $5 / 10(50 \%)$ & $4 / 11(36 \%)$ & $5 / 10(50 \%)$ \\
\hline CLD at $36 \mathrm{wk}$ & $2 / 9 * *(22 \%)$ & $2 / 10(20 \%)$ & $4 / 11(36 \%)$ & $3 / 10(30 \%)$ \\
\hline Chorioamnionitis* & $6 / 10(60 \%)$ & $4 / 10(40 \%)$ & $0 / 11(0 \%)$ & $0 / 10(0 \%)$ \\
\hline Funisitis* & $7 / 10(70 \%)$ & $3 / 10(30 \%)$ & $0 / 10(0 \%)$ & $0 / 7(0 \%)$ \\
\hline
\end{tabular}

RDS, respiratory distress syndrome.

$* p$ Value $<0.005$.

** One infant death at $24 \mathrm{~h}$.

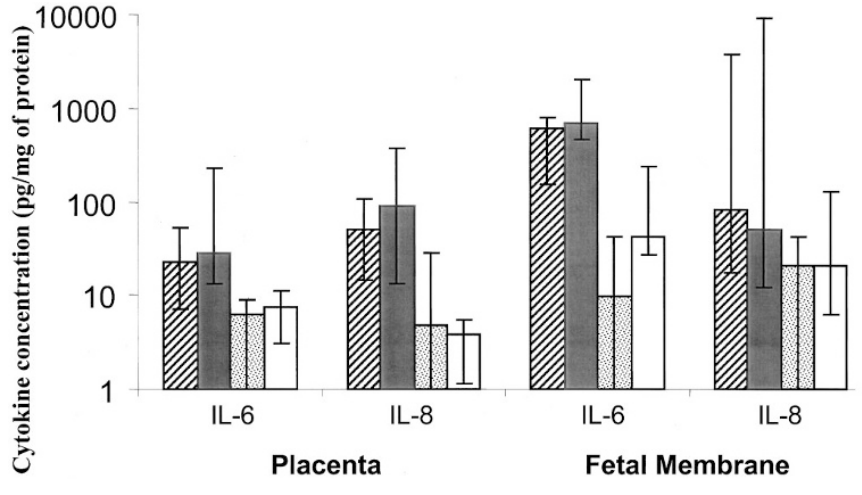

Figure 4. Concentration of IL-6 and IL-8 in placenta and fetal membrane from mother/baby from the pPROM (hatched bars), spontaneous preterm labor (shaded bars), nonlaboring preterm (dotted bars), and preterm twin groups (open bars). Concentration of cytokine is given per milligram of protein.

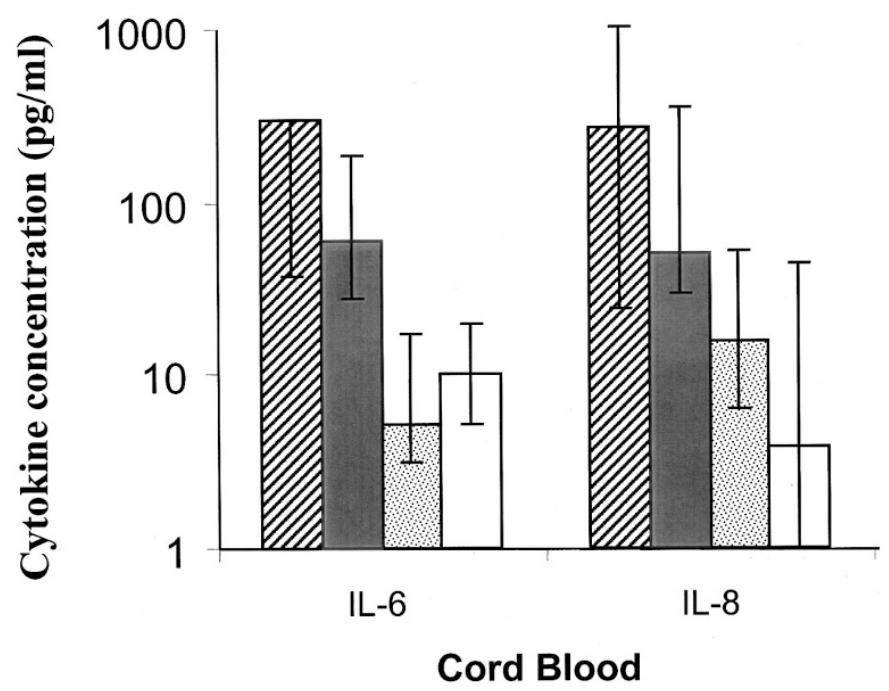

Figure 5. Concentration of IL-6 and IL-8 in cord blood from mother/baby from the pPROM (hatched bars), spontaneous preterm labor (shaded bars), nonlaboring preterm (dotted bars), and preterm twin groups (open bars).

less common as a mechanism of preterm labor in twin pregnancies (5), and that a stretch mechanism may be the underlying cause of preterm delivery in multiple pregnancies.

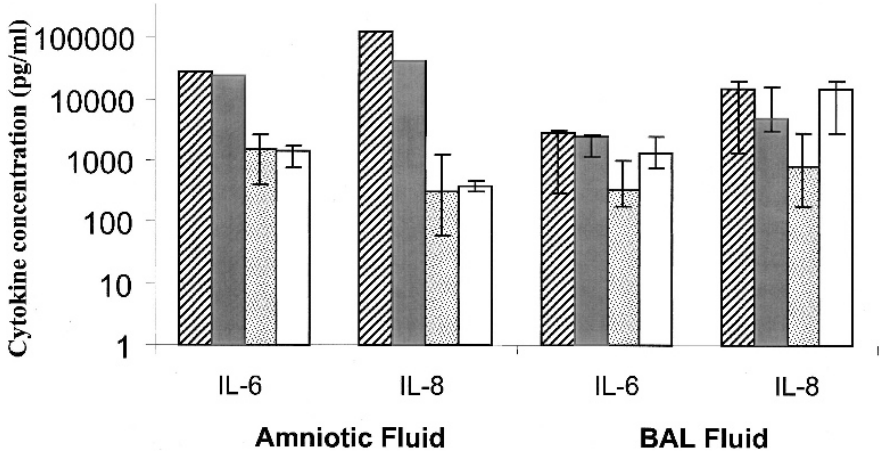

Figure 6. Concentration of IL-6 and IL-8 in amniotic fluid and BAL fluid from mother/baby from the pPROM (hatched bars), spontaneous preterm labor (shaded bars), nonlaboring preterm (dotted bars), and preterm twin groups (open bars).

We have sequenced the PCR products of the amplified 16s rRNA genes and have identified the closest relatives of the sequences using published databases. Most of these close relatives we have identified have been associated with clinical infections. U. urealyticum, Streptococcus agalactiae (Group B Streptococcus), and S. pneumoniae are well-known pathogens. Inasmuch as periodontal disease may be associated with preterm labor, the identification of the normal oral inhabitants Acinetobacter spp., Peptostreptoccus spp., and Leptotrichia spp. in intrauterine samples is an interesting observation (50). Streptococcus milleri, also a beta-haemolytic, has been isolated from many infective sites and Gardnerella spp., commensals of the vaginal tract, are associated with vaginosis and possibly preterm labor and intrauterine infection.

Increased concentrations of inflammatory markers IL-6 and IL-8 in amniotic fluid have been previously related to preterm delivery $(23,24)$. More specifically, elevations in both IL-8 and IL-6 have been associated with microbial invasion of the amniotic cavity in both pPROM (40) and preterm labor (39). Increased IL- 6 concentration in the fetus has suggested the presence of a fetal inflammatory response, and a role for the fetus in preterm labor (25). We have identified higher levels of IL-8 and IL-6 associated with microbial presence in placenta, fetal membranes, cord blood serum, and BAL fluid, suggesting 
that both mother and baby are exhibiting an inflammatory response. The association of increased cytokines with preterm labor and pPROM is consistent with the high rate of detection of microbes among these groups.

Among the tissue and fluid samples used in this study were BAL fluid and neonatal gastric fluid wherever possible. Previous work examining the role of infection in preterm labor has almost exclusively examined amniotic fluid. This involves amniocentesis to obtain amniotic fluid, a procedure not routinely used in the management of preterm labor in the UK. As the amniotic fluid could be considered in continuum with fetal lung fluid and gastric fluid, microbes present within amniotic fluid could also theoretically be isolated from these latter sources. Fetal lung fluid can only be obtained by BAL from neonates who are ventilated, whereas gastric fluid is readily obtained from all newborn infants. Amniotic fluid was not obtained from the majority of patients in this study, thus preventing a direct comparison of the use of amniotic fluid with gastric fluid in the detection of infection. However, the results obtained from gastric fluid correlated completely with the presence/absence of chorioamnionitis. This is the first time that gastric fluid has been suggested as an alternative to amniotic fluid in the investigation of infection in preterm labor. There remains a need to examine the relationship between infection detected in gastric fluid and subsequent neonatal outcome. This approach would not have any clinical utility antenatally but could be used in the management of the newborn infant if the results were found to be associated with neonatal outcome. It would be useful as a research tool in future studies relating to infection and preterm delivery, to act as a surrogate for amniotic fluid and avoid amniocentesis.

There is increasing evidence implicating antenatal intrauterine infection in the pathogenesis of neonatal disease, particularly cerebral white matter lesions (51) and the development of CLD (11). In addition, it has been postulated that the pulmonary inflammation observed in preterm infants who develop CLD $(26,27,52)$ in many instances may arise from antenatal infection (53). In this study, CLD was not associated with the development of respiratory distress syndrome, CLD, need for mechanical ventilation, or other neonatal outcomes, although to demonstrate such an association would require much larger numbers.

This work combines the use of PCR and a novel fluid, gastric fluid, to improve detection of infection associated with preterm labor. Although this may not have any direct utility in antenatal treatment of preterm labor and pPROM, it may have use in the neonatal treatment and may be used in research in place of amniotic fluid. Larger studies to confirm this work, and to relate the results to neonatal outcomes, will help define the utility of this approach.

Acknowledgments. The authors thank the mothers, babies, and staff from the maternity and neonatal units at the Leicester Royal Infirmary, Leicester. We would also like to thank Dr. Pat McEveer, pediatric pathologist at the Leicester Royal Infirmary, for histologic reporting on the placentas, fetal membranes, and umbilical cords.

\section{REFERENCES}

1. Goldenberg RL 2002 The management of preterm labour. Obstet Gynecol 100:1020 1037

2. Manktelow BN, Draper ES, Annamalai S, Field D 2001 Factors affecting the incidence of chronic lung disease of prematurity in 1987, 1992, and 1997. Arch Dis Child Fetal Neonatal Ed 85:F33-F35

3. Wood NS, Marlow N, Costeloe K, Gibson AT, Wilkinson AR 2000 Neurologic and developmental disability after extremely preterm birth. EPICure Study Group. N Engl J Med 343:378-384

4. Goldenberg RL, Hauth JC, Andrews WW Intrauterine infection and preterm delivery. N Engl J Med 342:1500-1507, 2000

5. Romero R, Espinoza J, Chaiworapongsa T, Kalache K 2002 Infection and prematurity and the role of preventive strategies. Semin Neonatol 7:259-274

6. Yoon BH, Romero R, Yang SH, Jun JK, Kim IO, Choi JH, Syn HC 1996 Interleukin-6 concentrations in umbilical cord plasma are elevated in neonates with white matter lesions associated with periventricular leukomalacia. Am J Obstet Gynecol 174:1433-1440

7. Yoon BH, Jun JK, Romero R, Park KH, Gomez R, Choi JH, Kim IO 1997 Amniotic fluid inflammatory cytokines (interleukin-6, interleukin- 1beta, and tumor necrosis factor-alpha), neonatal brain white matter lesions, and cerebral palsy. Am J Obstet Gynecol 177:19-26

8. Leviton A, Paneth N, Reuss ML, Susser M, Allred EN, Dammann O, Kuban K, Van Marter LJ, Pagano M, Hegyi T, Hiatt M, Sanocka U, Shahrivar F, Abiri M, Disalvo D, Doubilet P, Kairam R, Kazam E, Kirpekar M, Rosenfeld D, Schonfeld S, Share J, Collins M, Genest D, Shen-Schwarz S, et al. 1999 Maternal infection, fetal inflammatory response and brain damage in very low birth weight infants. Developmental Epidemiology Network Investigators. Pediatr Res 46:566-575

9. Lyon A 2000 Chronic lung disease of prematurity. The role of intra-uterine infection. Eur J Pediatr 159:798-802

10. Jobe AH, Ikegami M 2001 Antenatal infection/inflammation and postnatal lung maturation and injury. Respir Res 2:27-32

11. Miralles RE, Hodge R, Kotecha S 2002 Antenatal inflammation and infection in chronic lung disease of prematurity. Child Care Health Dev 28:11-15

12. Lettieri L, Vintzileos AM, Rodis JF, Albini SM, Salafia CM 1993 Does "idiopathic" preterm labor resulting in preterm birth exist? Am J Obstet Gynecol 168:1480-1485

13. Hillier SL, Krohn MA, Cassen E, Easterling TR, Rabe LK, Eschenbach DA 1995 The role of bacterial vaginosis and vaginal bacteria in amniotic fluid infection in women in preterm labor with intact fetal membranes. Clin Infect Dis 20:S276-S278

14. Pankuch GA, Appelbaum PC, Lorenz RP, Botti JJ, Schachter J, Naeye RL 1984 Placental microbiology and histology and the pathogenesis of chorioamnionitis. Obstet Gynecol 64:802-806

15. Hillier SL, Martius J, Krohn M, Kiviat N, Holmes KK, Eschenbach DA 1988 A case-control study of chorioamnionic infection and histologic chorioamnionitis in prematurity. N Engl J Med 319:972-978

16. Hillier SL, Witkin SS, Krohn MA, Watts DH, Kiviat NB, Eschenbach DA 1993 The relationship of amniotic fluid cytokines and preterm delivery, amniotic fluid infection, histologic chorioamnionitis, and chorioamnion infection. Obstet Gynecol 81:941-948

17. Bernischke K, Kaufman P. 2000 Pathology of the Placenta, 4th Ed. Springer-Verlag, New York, pp 591-684

18. Jalava J, Mantymaa ML, Ekblad U, Toivanen P, Skurnik M, Lassila O, Alanen A 1996 Bacterial 16S rDNA polymerase chain reaction in the detection of intra-amniotic infection. Br J Obstet Gynaecol 103:664-669

19. Hitti J, Riley DE, Krohn MA, Hillier SL, Agnew KJ, Krieger JN, Eschenbach DA 1997 Broad-spectrum bacterial rDNA polymerase chain reaction assay for detecting amniotic fluid infection among women in premature labor. Clin Infect Dis 24:12281232

20. Markenson GR, Martin RK, Tillotson-Criss M, Foley KS, Stewart RS Jr, Yancey M 1997 The use of the polymerase chain reaction to detect bacteria in amniotic fluid in pregnancies complicated by preterm labor. Am J Obstet Gynecol 177:1471-1477

21. Oyarzun E, Yamamoto M, Kato S, Gomez R, Lizama L, Moenne A 1998 Specific detection of 16 micro-organisms in amniotic fluid by polymerase chain reaction and its correlation with preterm delivery occurrence. Am J Obstet Gynecol 179:11151119

22. Kotecha S, Hodge R, Schaber JA, Miralles R, Silverman M, Grant WD 2004 Pulmonary ureaplasma urealyticum is associated with the development of acute lung inflammation and chronic lung disease in preterm infants. Pediatr Res 55:61-68

23. El-Bastawissi AY, Williams MA, Riley DE, Hitti J, Krieger JN 2000 Amniotic fluid interleukin-6 and preterm delivery: a review. Obstet Gynecol 95:1056-1064

24. Romero R, Ceska M, Avila C, Mazor M, Behnke E, Lindley I 1991 Neutrophil attractant/activating peptide-1/interleukin- 8 in term and preterm parturition. Am J Obstet Gynecol 165:813-820

25. Romero R, Gomez R, Ghezzi F, Yoon BH, Mazor M, Edwin SS, Berry SM 1998 A fetal systemic inflammatory response is followed by the spontaneous onset of preterm parturition. Am J Obstet Gynecol 179:186-193

26. Kotecha S, Wangoo A, Silverman M, Shaw RJ 1996 Increase in the concentration of transforming growth factor beta-1 in bronchoalveolar lavage fluid before development of chronic lung disease of prematurity. J Pediatr 128:464-469

27. Kotecha S, Wangoo A, Silverman M, Shaw RJ 1996 Increase in interleukin (IL)-1 beta and IL-6 in bronchoalveolar lavage fluid obtained from infants with chronic lung disease of prematurity. Pediatr Res 40:250-256

28. de Blic J, Midulla F, Barbato A, Clement A, Dab I, Eber E, Green C, Grigg J, Kotecha S, Kurland G, Pohunek P, Ratjen F, Rossi G 2000 Bronchoalveolar lavage in children. ERS Task Force on bronchoalveolar lavage in children. European Respiratory Society. Eur Respir J 15:217-231 
29. Yoon BH, Romero R, Moon JB, Shim SS, Kim M, Kim G, Jun JK 2001 Clinical significance of intra-amniotic inflammation in patients with preterm labor and intact membranes. Am J Obstet Gynecol 185:1130-1136

30. Yoon BH, Romero R, Park JS, Kim M, Oh SY, Kim CJ, Jun JK 2000 The relationship among inflammatory lesions of the umbilical cord (funisitis), umbilical cord plasma interleukin-6 concentration, amniotic fluid infection, and neonatal sepsis. Am J Obstet Gynecol 183:1124-1129

31. Blanchard A, Hentschel J, Duffy L, Baldus K, Cassell GH 1993 Detection of Ureaplasma urealyticum by polymerase chain reaction in the urogenital tract of adults, in amniotic fluid, and in the respiratory tract of newborns. Clin Infect Dis 17:S148-S153

32. Sacks NP, Smith K, Norman AP, Greenall M, LeJeune S, Harris AL 1993 Cathepsin $\mathrm{D}$ levels in primary breast cancers: relationship with epidermal growth factor receptor, oestrogen receptor and axillary nodal status. Eur J Cancer 29A:426-428

33. Altshuler G, Hyde S 1988 Clinicopathologic considerations of fusobacteria chorioamnionitis. Acta Obstet Gynecol Scand 67:513-517

34. Watts DH, Krohn MA, Hillier SL, Eschenbach DA 1992 The association of occult amniotic fluid infection with gestational age and neonatal outcome among women in preterm labor. Obstet Gynecol 79:351-357

35. Andrews WW, Hauth JC, Goldenberg RL, Gomez R, Romero R, Cassell GH 1995 Amniotic fluid interleukin-6: correlation with upper genital tract microbial colonization and gestational age in women delivered after spontaneous labor versus indicated delivery. Am J Obstet Gynecol 173:606-612

36. Romero R, Salafia CM, Athanassiadis AP, Hanaoka S, Mazor M, Sepulveda W, Bracken MB 1992 The relationship between acute inflammatory lesions of the preterm placenta and amniotic fluid microbiology. Am J Obstet Gynecol 166:13821388

37. Romero R, Avila C, Santhanam U, Sehgal PB 1990 Amniotic fluid interleukin 6 in preterm labor. Association with infection. J Clin Invest 85:1392-1400

38. Romero R, Yoon BH, Mazor M, Gomez R, Gonzalez R, Diamond MP, Baumann P, Araneda H, Kenney JS, Cotton DB, Sehgal P 1993 A comparative study of the diagnostic performance of amniotic fluid glucose, white blood cell count, interleukin-6, and Gram stain in the detection of microbial invasion in patients with preterm premature rupture of membranes. Am J Obstet Gynecol 169:839-851

39. Jacobsson B, Mattsby-Baltzer I, Andersch B, Bokstrom H, Holst RM, Wennerholm UB, Hagberg H 2003 Microbial invasion and cytokine response in amniotic fluid in a Swedish population of women in preterm labor. Acta Obstet Gynecol Scand $82: 120-128$

40. Jacobsson B, Mattsby-Baltzer I, Andersch B, Bokstrom H, Holst RM, Nikolaitchouk N, Wennerholm UB, Hagberg H 2003 Microbial invasion and cytokine response in amniotic fluid in a Swedish population of women with preterm prelabor rupture of membranes. Acta Obstet Gynecol Scand 82:423-431

41. Yoon BH, Romero R, Moon J, Chaiworapongsa T, Espinoza J, Kim YM, Edwin S, Kim JC, Camacho N, Bujold E, Gomez R 2003 Differences in the fetal interleukin-6 response to microbial invasion of the amniotic cavity between term and preterm gestation. J Matern Fetal Neonatal Med 13:32-38

42. Yoon BH, Romero R, Kim CJ, Jun JK, Gomez R, Choi JH, Syn HC 1995 Amniotic fluid interleukin-6: a sensitive test for antenatal diagnosis of acute inflammatory lesions of preterm placenta and prediction of perinatal morbidity. Am J Obstet Gynecol 172:960-970

43. Arntzen KJ, Kjollesdal AM, Halgunset J, Vatten L, Austgulen R 1998 TNF, IL-1, IL-6, IL-8 and soluble TNF receptors in relation to chorioamnionitis and premature labor. J Perinat Med 26:17-26

44. Tsuda A, Ikegami T, Hirano H, Sanada H, Ogawa M, Sasaki M, Tanaka T 1998 The relationship between amniotic fluid interleukin-6 concentration and histologic evidence of chorioamnionitis. Acta Obstet Gynecol Scand 77:515-520

45. Rogers BB, Alexander JM, Head J, McIntire D, Leveno KJ 2002 Umbilical vein interleukin-6 levels correlate with severity of placental inflammation and gestational age. Hum Pathol 33:335-340

46. Dollner H, Vatten L, Halgunset J, Rahimipoor S, Austgulen R 2002 Histologic chorioamnionitis and umbilical serum levels of pro-inflammatory cytokines and cytokine inhibitors. BJOG 109:534-539

47. Odibo AO, Rodis JF, Sanders MM, Borgida AF, Wilson M, Egan JF, Campbell WA 1999 Relationship of amniotic fluid markers of intra-amniotic infection with histopathology in cases of preterm labor with intact membranes. J Perinatol 19:407-412

48. Mueller-Heubach E, Rubinstein DN, Schwarz SS 1990 Histologic chorioamnionitis and preterm delivery in different patient populations. Obstet Gynecol 75:622-626

49. Ghidini A, Salafia CM, Minior VK 1998 Lack of relationship between histologic chorioamnionitis and duration of the latency period in preterm rupture of membranes. J Matern Fetal Med 7:238-242

50. Lopez NJ, Smith PC, Gutierrez J 2002 Higher risk of preterm birth and low birth weight in women with periodontal disease. J Dent Res 81:58-63

51. Yoon BH, Park CW, Chaiworapongsa T 2003 Intrauterine infection and the development of cerebral palsy. BJOG 110:S124-S127

52. Kotecha S, Chan B, Azam N, Silverman M, Shaw RJ 1995 Increase in interleukin-8 and soluble intercellular adhesion molecule-1 in bronchoalveolar lavage fluid from premature infants who develop chronic lung disease. Arch Dis Child Fetal Neonatal Ed 72:F90-F96

53. Speer CP 2001 New insights into the pathogenesis of pulmonary inflammation in preterm infants. Biol Neonate 79:205-209 